\title{
Resource heterogeneity and community structure: A case study in Heliconia imbricata Phytotelmata
}

\author{
Shahid Naeem * \\ Department of Zoology, University of California, Berkeley, CA 94720, USA
}

Received July 6, 1989 / Accepted in revised form March 9, 1990

Summary. Complex or non-additive differences in the distribution and abundance of arthropod species inhabiting the water-filled bracts of Heliconia imbricata can be created by simple manipulations of resource levels. The primary resources for these assemblages are the corollas of the flowers that accumulate in the bracts. Removing or adding corollas to individual bracts changes the pattern in the abundance of arthropod species within each bract such that bracts with different treatments ultimately differ in composition and numerical associations among species. These results suggest that direct and indirect resource-mediated factors can structure or significantly affect the distribution and abundance of species in these and perhaps other assemblages. Thus, in natural communities, if resources are heterogeneous among patches (such as among the bracts in this study), structure in a given patch may be a function of the resource level of that patch and can differ significantly from neighboring patches that provide different resource levels.

Key words: Community ecology - Heliconia imbricata - Phytotelmata - Resource heterogeneity - Arthropods

Much attention in community ecology has focused on the effects of environmental heterogeneity on community structure, patterns in the distribution and abundance of species in a community determined by ecological or evolutionary processes. Many of the effects of environmental heterogeneity uncovered so far are those that modify the outcomes of biotic interactions as they are predicted by Lotka-Voltera-type models, most of which assume environmental constancy. For example, spatial or temporal heterogeneity can alter the outcome of competition (e.g. Hutchinson 1961; Levins 1968; Slatkin

* Present address and address for offprint requests: Department of Biology, The University of Michigan, Ann Arbor, MI 481091048, USA
1974; Shorrocks et al. 1979; Atkinson and Shorrocks 1981) or predation (e.g. Huffaker 1958; Caswell 1978; Morin et al. 1983) or both (e.g. Holt 1977, 1984; Jeffries and Lawton 1984). Heterogeneity in the form of disturbance can prevent competitive exclusion (e.g. Connell 1978; Sousa 1979 a, b, 1984).

Resource heterogeneity, as a form of environmental heterogeneity, has received less attention. Many laboratory studies that have examined biotic interactions have held resource levels constant by adding or renewing resources during the experiment while manipulating communities (see, for examples, Gause 1934; Park 1948; Neil 1975; Luckinbill 1978, 1979; Murdoch and McCauley 1985). Other studies have allowed resource levels to change, but set homogeneous initial resource conditions among treatments while manipulating community composition (e.g. Wilbur 1982; Morin 1983; Semlitsch 1987). Yet there is evidence, both experimental and theoretical, that different resource levels qualitatively affect the structure of communities (Levins 1979; Tilman 1982; Chesson 1986), suggesting that the studies listed above might have yielded different results at different resource levels.

In this study, I examine the effects of resource heterogeneity on an assemblage of species whose interactions include mutualism, predation, and competition. Specifically, I address the following question: are there simple or complex, predictable or unpredictable changes in the patterns of distribution and abundance of species in assemblages when resource levels change? By "simple" I mean uniform changes in species abundances that correlate with changes in resources. "Complex" changes would include qualitatively different non-linear or nonadditive responses by different species to a change in resource level. "Predictable" changes would be those responses to changes in resource level that can be predicted given information on the change in resources.

Some communities are better suited for addressing this question than others. Communities of "decomposers" that use discrete patches of organic material as resources can be readily censused and manipulated. 
A wide variety of decomposer communities have been studied (see, for review, Swift et al. 1979; Kikkawa and Anderson 1986). One class of such communities is the phytotelm community, defined as the community of organisms found living in plant-held bodies of water (Maguire 1971). Phytotelmata offer advantages over other discrete communities because phytotelmata are small in size; frequently species rich; easy to locate replicates, readily manipulated and observed; and there is a wealth of literature that provides background information on the biology of many of these systems (see, for review, Maguire 1971, references in Fish and Beaver 1978, and papers in Frank and Lounibos 1983).

In this study I examine the effects of resource heterogeneity on a small assemblage of arthropods that inhabit the water filled bracts of the inflorescences of Heliconia imbricata (Musaceae), a neotropical banana-like plant. These bracts are commonly inhabited by a wide variety of insects (Seifert 1982, 1984). The main resource of the $H$. imbricata phytotelmata is the floral material that collects and decomposes in the bracts. Such a resource makes $H$. imbricata phytotelmata ideal for the study of resource heterogeneity because the resources (corollas) can be readily censused and easily manipulated.

\section{Materials and methods}

\section{Study site}

This study was carried out along Sendero Occidental and Sendero Oriental, trails parallel to the Rio Puerto Viejo. This river borders the northeast part of Estacion Biologia Finca La Selva, Costa Rica, $\left(10^{\circ} 24-26^{\prime} \mathrm{N}, 84^{\circ} 00-02^{\prime} \mathrm{W}\right)$ a lowland tropical rainforest field station owned and operated by the Organization for Tropical Studies (see Janzen 1983 for a thorough discussion of this field site).

\section{Study organisms}

$H$, imbricata. These plants grow in open, second-growth habitats, frequently along trails and in other disturbed areas. They also grow along natural openings such as those near streams or those caused by tree falls. $H$. imbricata grows in clones connected by thick rhizomes. Inflorescences consist of stacked (imbricate) cincinnal bracts, or branch bracts, that sheath clusters of axillary flower buds. Old inflorescences can contain up to 40 bracts but old bracts at the base eventually cease flowering, rip open, expose the fruits that turn blue when ripe. Bracts of this age no longer carry fluid. Inflorescences are annual, produced between April and December with a peak in flowering in July and August during the rainy season (Daniels and Stiles 1979).

Fluid found in the bract is produced by the plant (Bronstein 1986). The fluid is undoubtedly augmented by rain that enters obliquely, but direct entry of rain is limited because each bract is shielded by the bracts above them and the topmost bracts are closed. Thus, fluid levels are relatively stable and intact bracts do not dry out.

Flowers open early $(05: 00 \mathrm{~h})$ and remain with their tips above the fluid, exposed to pollination by hummingbirds, throughout most of the day. A single bract generally has only one open flower at any given time but may produce up to 15 over its lifespan (see Results for phenology). Corollas are firmly attached to the ovaries and cannot be removed easily during the day. Corollas abscise, however, at their bases by late afternoon (15:00) and can be removed easily with a gentle tug. During the following night, the corolla doubles over and withdraws into the bract, but does not fall out of the bract. Within a day or two the old corollas become detached from the ovaries and fall to the bottom of the bract.

In this paper "corolla" is used to simplify the text, though this terminology is not quite accurate. In fact, what I will call the "corolla" contains the androecium and the pistil which remain attached to the true corolla (petals) after it detaches from the ovary.

\section{Resources other than corollas}

Most of the arthropod species feed directly or indirectly (as detritivores) on the fallen corollas. Not all species in this community, however, depend on the corollas. Hispine beetle adults and larvae, and hydrophilid beetle adults feed on the inner surfaces of the bracts. I refer to tese species as "bract scourers". The scouring activity of these insects produces an additional source of food for scavengers and filter feeders since they grind up and process bract tissue and deposit feces in the bract. Seifert and Seifert (1976) showed that hispine beetle larvae had a positive effect on the abundance of several species in the community. Hydrophilid adults undoubtedly have a similar effect but they cannot be censused accurately because of their rapid flight when an inflorescence or bract is disturbed. Though Seifert and Seifert (1976) referred to hispines as mutualists, I classify bract scourers functionally as facilitators, because it is not clear that hispines derive any benefit from the species whose existence they facilitate.

\section{Arthropods}

Table 1 lists the species examined in this study. Table 1 also briefly describes the biology of these species in relation to the resources. Further information on the biology of the insects can be found in Seifert and Seifert $(1976 \mathrm{a}, \mathrm{b})$. Figure 1 presents a food web for this system and indicates which links are either observed or hypothetical. There were a large number of incidental arthropod species (about 20 other spp.) found in the inflorescences that were too rare to include in the analyses. The arthropods examined here were chosen because their abundance suggested that they were the functionally significant species in the assemblage.

To simplify the text I will refer to the various species by family (syrphid, stratiomyid, richardiid, chironomid, hydrophilid, anoetid, algophagid) or common names (mosquito, hispine, copepod) that are likely to be more familiar to the reader than the generic and specific names listed in Table 1. I will also refer to mites and copepods collectively as "micro-arthropods" and to insect larvae collectively as "macro-arthropods".

Other species in this system are primarily microbes. These microbes compete with or serve as prey for arthropods. But microbes, though important in the overall process of decomposition of the resources, are not likely be important in structuring the assemblages of arthropods. Arthropods in leaf litter, for example, are the dominant organisms determining the rates of resource use in litter decomposition communities (Edwards and Heath 1963; Witkamp and Crossley 1966; Coughtrey et al. 1979). To be sure, microbial dynamics are a significant component of litter decomposition communities, but their dynamics are determined in large part by physical and chemical alterations of decaying plant material by arthropods (Satchell 1974; Visser 1986; Hassall et al. 1987).

\section{Censusing the resource and its heterogeneity}

At approximately biweekly intervals, I censused inflorescences by counting the bracts on all inflorescences clearly seen from the trail along Sendero Occidental and Sendero Oriental. To census flower productivity I randomly chose 30 inflorescences from the three clones used in this study and recorded daily the flowers produced by each bract on each inflorescence throughout the study period. 
Table 1. Species of arthropods from Heliconia imbricata examined used in this study. Footnotes refer to authorities who assisted in identification

\begin{tabular}{|c|c|c|}
\hline Family & Species & Biology \\
\hline \multicolumn{3}{|c|}{ Class: Insecta (Diptera) } \\
\hline Richardiidae $^{a}$ & Beebeomyia n. sp. & Scavenger. Lives mostly between buds and pappery bracts sheathing buds \\
\hline Syrphidae ${ }^{\mathrm{b}}$ & Quichauana calathea & Scavenger. Lives in fluid below and within flowers and buds \\
\hline Stratiomyidae ${ }^{c}$ & Merosargus rossi & Scavenger. Lives within old and new flowers \\
\hline Chironimidae $^{\mathrm{d}}$ & Pentaneura n. sp. & Predator. Feeds, most likely, on copepods and mosquitoes \\
\hline Chrysomelidae: & Hispinae Cephaloleia & Bract scourers \\
\hline $\begin{array}{l}\text { Hydrophilidae: } \\
\text { Class: Arachnida }\end{array}$ & Gillisius & Juvenile - predator. Feeds on dipteran larvae. Adult - bract scourer \\
\hline Anoetidae ${ }^{\mathrm{f}}$ & Histiostoma (n. sp) & Scavenger. Lives within decomposing flowers \\
\hline Algophagidae $^{\mathrm{f}}$ & Fusohericia (n. sp) & Scavenger. Lives within decomposing flowers \\
\hline
\end{tabular}

${ }^{a}$ D. Grimaldi, ${ }^{b}$ F.C. Thompson, ${ }^{\text {c }}$ W.J. Hanson, ${ }^{\text {d }}$ J.E. Sublette, ${ }^{\mathrm{e}}$ T.J. Zavortink, ${ }^{\mathrm{f}}$ B.M. OConnor, ${ }^{\mathrm{g}}$ R. Black

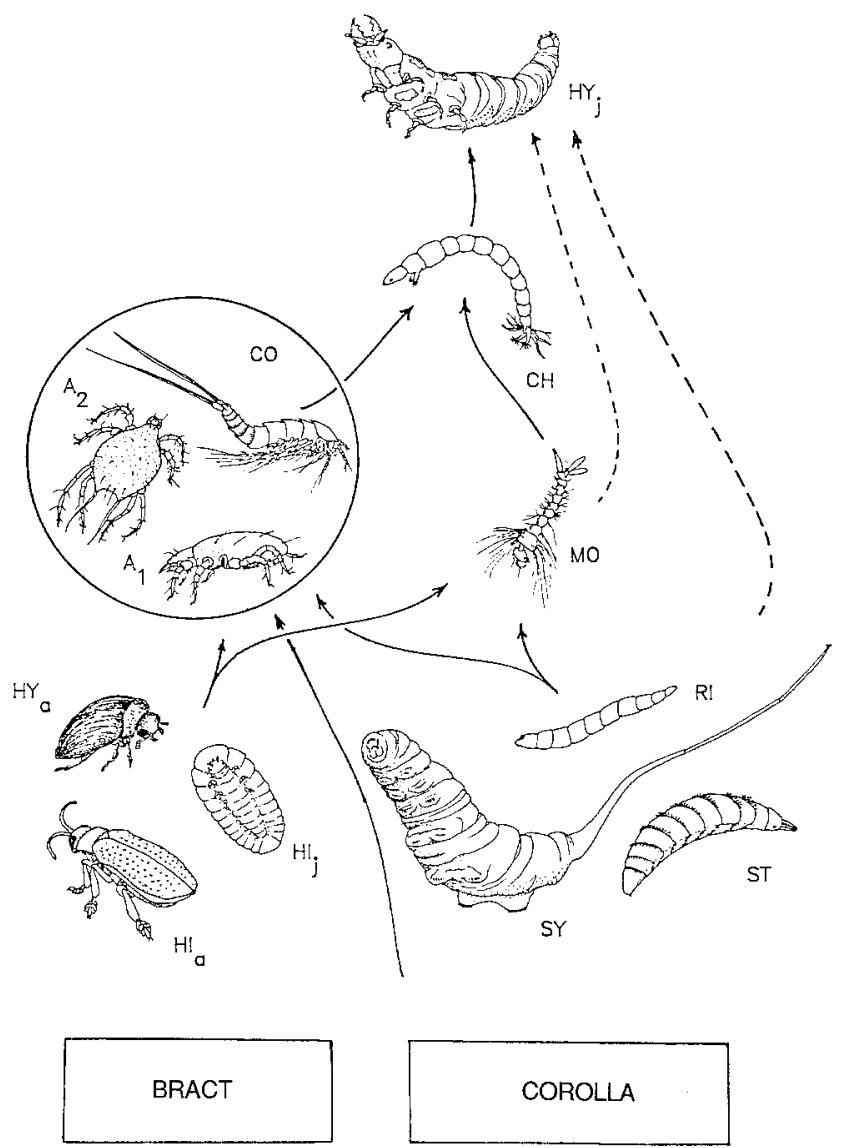

Fig. 1. Food web of Heliconia imbricata arthropod assemblage. Arthorpods illustrated in this figure are listed in Table 1 with their association with bract or corolla resources in $H$. imbricata bracts. Solid arrows indicate direction of energy flow. Dashed arrows indicate hypothetical (unobserved) direction of energy flow. $A_{1}=$ anoetid mite; $A_{2}=$ algophagid mite; $C H=$ chronomid ; $C O=$ copepod; $H I_{a}=$ hispine beetle, adult; $H I_{j}=$ hispine beetle, larva; $H Y_{a}=$ hyd rophilid beetle, adult; $H Y_{j}=$ hydrophilid beetle, larva; $M O=$ mosquito; $R I=$ richardiid larva; $S T=$ stratiomyid larva; $S Y=$ syrphid larva

\section{Manipulating the resource}

To examine the importance of resource level on community structure I manipulated resource levels and monitored the effects on the assemblages by comparing the resource-manipulated bracts to unmanipulated bracts. Two possible types of differences might occur; (1) diminishing or augmenting resources would uniformly decrease or increase, respectively, population sizes of all species ("simple" changes defined above), or (2) different species would show different responses to the manipulations ("complex" changes).

Twenty inflorescences were chosen for these experiments. These 20 were divided into 5 blocks of 4 and within each block one of the following 4 treatments was randomly assigned:

(1) Diminished resources. All corollas were removed. These inflorescences also functioned as donor inflorescences for recipient inflorescences in treatment 2.

(2) Augmented resources. Corollas taken from inflorescences above were added to these inflorescences. Corollas were added to bracts in the same position on the inflorescence as the position on the inflorescence from which it was removed. If 2 or more corollas were produced within a donor bract then all corollas were added to the recipient bract.

\section{(3) Control. Corollas were unmanipulated.}

(4) Left-right. Corollas from the left bracts of the inflorescence were removed and added to corresponding position on the right of the inflorescence.

Inflorescences were left uncovered and were not manipulated in any other way. Corollas were removed shortly before complete abscission occurred. All bracts on a given inflorescence recieved the same treatment. Manipulations were conducted continuously for the duration of the experiment. Each block of treatments was followed for 4 weeks. The first block was started 16 June 1986 and each consecutive week another block was added. Thus, the entire experiment was carried out over a two month period well within the middle of the flowering season for $H$. imbricata (see above).

The first manipulation effectively stopped any new resources from accumulating within the bracts. The second manipulation doubled the natural corolla productivity of an inflorescence. Inflo- 


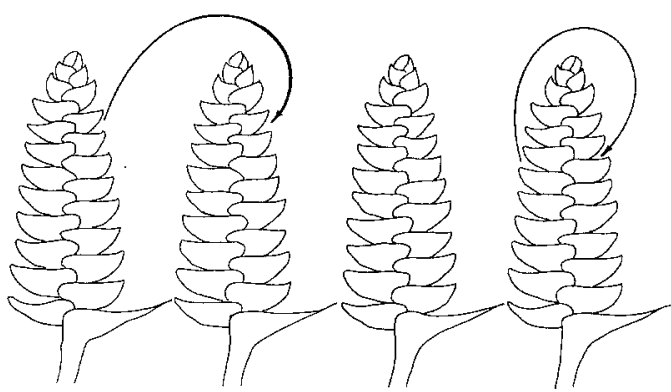

Fig. 2. Schematic outline of resource manipulations in Heliconia imbricata. Arrows indicate direction of transfer of corollas for the following treatments, from left to right: resource diminished, resource augmented, control, and left-right treatments. This figure illustrates transfer of single corollas. If more than one flower was produced on a given day then all corollas were transfered according to treatment. See text for further detail

rescences in the third set were unmanipulated and served as controls. These 3 provided bracts with high, normal, and low resource levels. The fourth and final manipulation created within-inflorescence resource heterogeneity. Figure 2 shows these manipulations.

The fourth treatment examines within-inflorescence resource heterogeneity. Some species can move from bract to bract more easily than others and may respond to resource manipulations differently than those species whose movements are restricted. Other treatments are homogeneous for all bracts within an inflorescence so that an arthropod moving among bracts in these inflorescences is not likely to experience different conditions among bracts. Unlike the other treatments, however, in the left-right treatment, moving to the right bract means encountering more resources. Note that at the end of the experiment the total number of corollas per inflorescence remained unchanged but the bracts on the left received approximately double the number of corollas (similar to the resource-augmented treatment) while those on the right had corolla input stopped (similar to the resource-diminished treatment) for the duration of the experiment.

The left to right transfer was an arbitrary convention to prevent accidentally moving corollas in the wrong direction. In no way does it represent a systematic bias in the way corollas were moved. Left to right in 3 instances meant moving corollas from odd to even numbered bracts and in 2 instances from even to odd numbered bracts. Inflorescences had no particular compass orientations so transfer direction of corollas was not in any particular compass direction. Since the bracts are intercalated (Fig. 2), however, corollas were always transferred to the bract above on the right. There were always young and empty bracts above but frequency ripped or no bracts below the bract from which the corolla was being transferred. This convention avoided the problem of having to throw a corolla away if it was produced on the bottom bract and was supposed to be moved down.

Inflorescences were checked daily for the presence of corollas. Corollas were manipulated daily between 15:00-18:00 according to their treatment assignment. At the end of the experiment, 6 bracts were collected, three from the left and three from the right, from each inflorescence and censused for all species, fully enumerating each species (i.e., estimates are not based on samples but are complete counts. I collected from the 10 most central bracts. These bracts reside in the central active part of inflorescence. Below the central portion bracts are old and contain no fluid. Above this portion bracts are young, open, but not yet producing open flowers. Previous censuses of these old and young bracts showed that they contain very few individuals of the species that are found throughout most of the other bracts.

Position of the bract within the central, active portion of the inflorescence potentially makes an important contribution to variation in communities found in the bracts. Bracts near the bottom of this region are older than bracts near the top. To examine this "age" factor I collected the 6 bracts from 3 paired positions (heights) in each inflorescence. Thus, the factor "height" has three levels in this study: (1) the bottom most, or oldest pair of the 10 most central bracts; (2) the middle pair; and (3) the highest, or youngest pair.

\section{Results}

\section{Censusing the resource and its heterogeneity}

The number of bracts per inflorescence increases at a steady rate throughout the season, new bracts being added to inflorescences at a rate of 2 to 3 per week (Fig. 3). The frequency distribution of inflorescences of different sizes, however, shows that heterogeneity in inflorescence size remains high throughout the season (Fig. 3).

Flower production is highest for the central bracts in young inflorescences (Fig. 4). The peak flower pro-
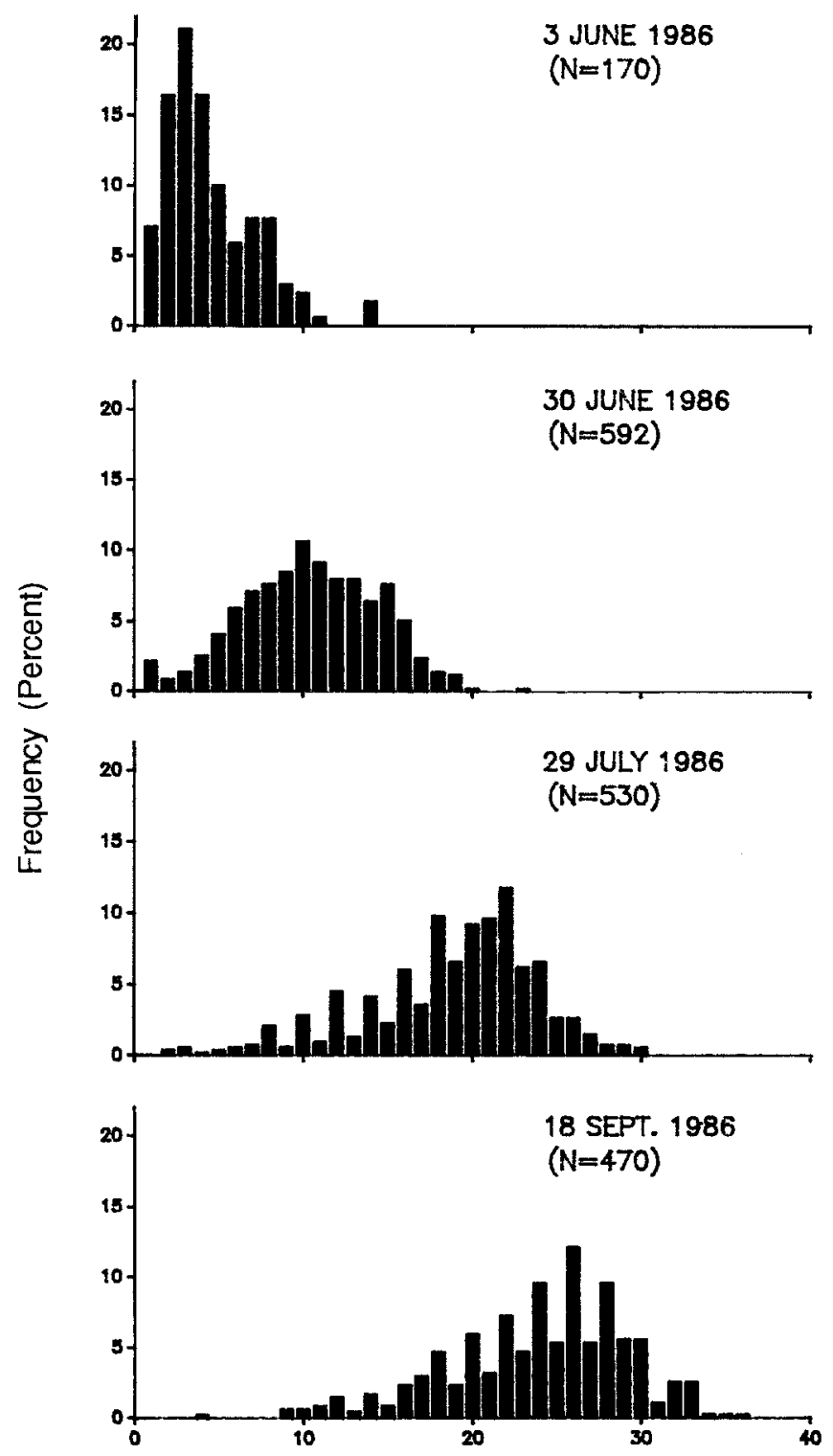

Number of bracts

Fig. 3. Inflorescence development of Heliconia imbricata over duration of study. Plots from top to bottom indicate frequency distributions for inflorescences of different sizes for all clones used in this study. See text for description of study site and censusing methods 


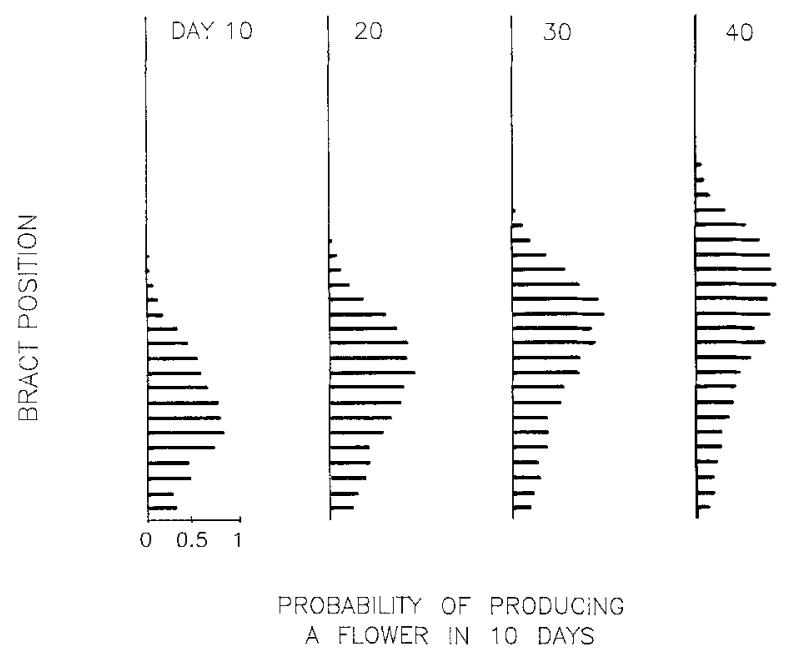

Fig. 4. Flower productivity in Heliconia imbricata based on 30 inflorescences. Bract position is indicated by horizontal lines perpendicular to the vertical lines. Bottom horizontal line indicates bottom bract. Each figure represents mean flowering pattern for all inflorescences at day $10,20,30$, and 40 , from left to right, respectively. Length of lines projecting to the right indicate the probability of producing a flower in 10 days. Longest line projecting to right in all figures indicates a probability of 1

ducing bracts of an inflorescence, however, shift in an upward direction as an inflorescence develops (Fig. 4). Although the inflorescence lengthens, the active portion of the inflorescence does not vary much in number of bracts regularly producing flowers. It was from this active region that I collected for sampling the inflorescence.

Position of the bract on the inflorescence, or "height", therefore represents 2 factors; (1) relative age of a bract and (2) a difference in flower productivity. The differences in productivity are desirable because this study focuses on the effects of such heterogeneity on community structure. Height as a factor of age, independent of productivity, however, could be a significant contributor to some of the variance in the experiments and the control. For this reason, I recorded bract height as "top", "middle", and "bottom" within the region that bracts were collected. This categorical variable was included in analyses of variance (below) to check for the possibility that bract age itself could significantly alter assemblage structure.

\section{Censuses of unmanipulated communities (control treatment)}

The "control" treatment provides information on the unmanipulated, natural patterns of community composition and the numerical relationships among species and their resources. Later sections will compare results from this section with the manipulated communities of the other 3 treatments.

Only 6 of the 10 arthropod species were sufficiently abundant for statistical analyses. Table 2 shows summary statistics for the census of species listed in Table 1 that were found in the control bracts. Note that richardiid, mosquito, and hydrophilid larvae were below a
Table 2. Summary statistics for variables used in this study. Data are taken from unmanipulated Heliconia imbricata bracts. See text for further information on species. S.E. = standard error, MIN = minimum, MAX $=$ maximum, sample size $=30$

\begin{tabular}{lrrlrr}
\hline Variable & Mean & \multicolumn{1}{c}{ S.E. } & MIN & MAX & Total \\
\cline { 2 - 4 } \cline { 5 - 6 } Syrphid & 1.40 & 1.54 & 0 & 5 & 42 \\
Stratiomyid & 0.93 & 1.19 & 0 & 5 & 37 \\
Richardiid & 0.57 & 0.73 & 0 & 3 & 17 \\
Chironomid & 1.70 & 1.77 & 0 & 8 & 51 \\
Mosquito & 0.10 & 0.55 & 0 & 3 & 3 \\
Hispine & 0.89 & 0.63 & 0 & 4 & 19 \\
Hydrophilid & 0.53 & 0.68 & 0 & 2 & 16 \\
Anoetid Mite & 53.60 & 85.32 & 0 & 395 & 1608 \\
Algophagid Mite & 10.17 & 16.10 & 0 & 52 & 305 \\
Copepod & 120.30 & 100.27 & 0 & 358 & 3609 \\
Fruits & 8.76 & 3.03 & 2 & 13 & 245 \\
Buds & 6.27 & 2.98 & 0 & 12 & 188 \\
\hline
\end{tabular}

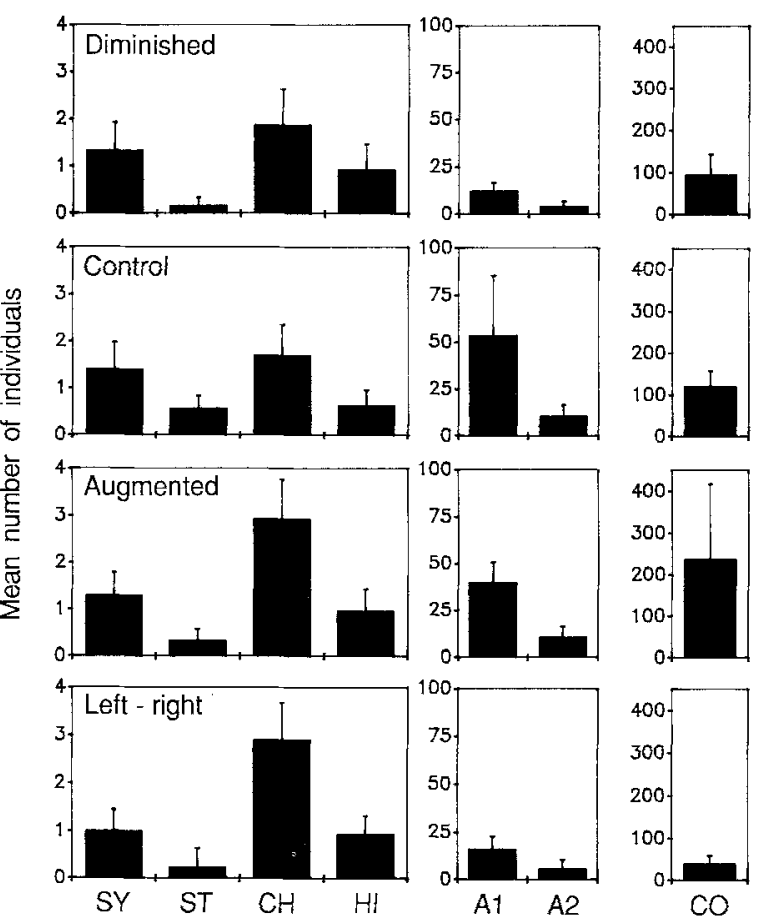

Fig. 5. Treatment means and $95 \%$ confidence intervals for arthropod species used in this study

mean of 1 per bract. These species were less than 0.7 per bract for all other treatments. Stratiomyids occurred at mean densities below 1 per bract in all other treatments other than the control (Fig. 5). I, therefore, excluded these 4 species from further analyses. Note, however, that hispines were reasonably close to a mean of 1 per bract in all treatments $(0.93,0.89,0.97$, and 0.93 for treatments $1-4$, respectively) so they were included in further analyses. Figure 5 plots the means and $95 \%$ confidence intervals for all treatment censuses. Of the six species remaining 4 are potential competitors (syrphids, anoetid mites, algophagid mites, and copepods), 1 is a predator (chironomid, Naeem 1988), and the other is a facilitator (hispine beetle larvae).

Few species individually show readily detectable associations with resources, as measured by the number 

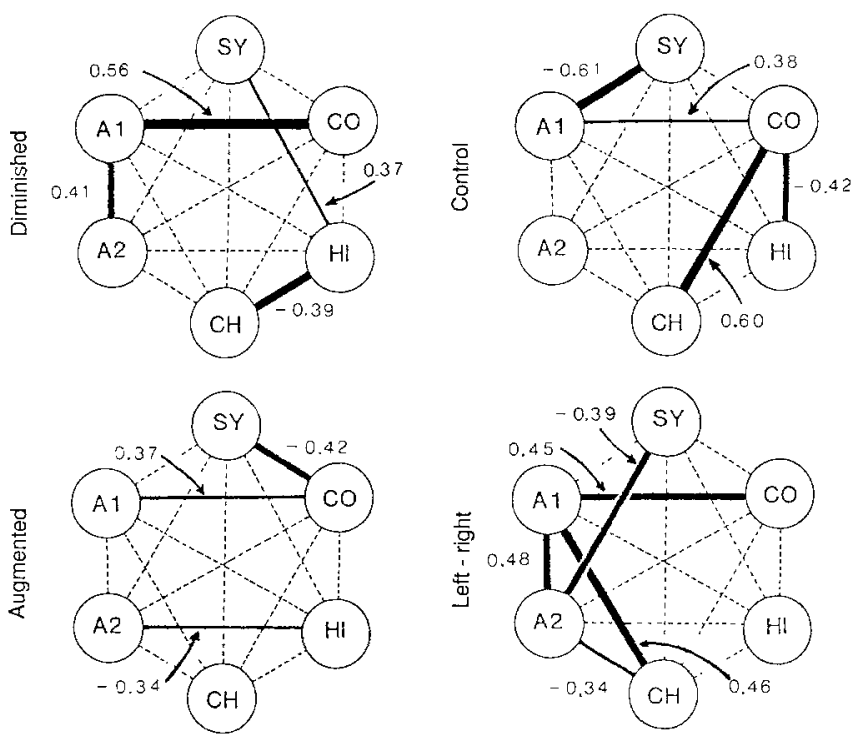

Fig. 6. Partial correlation diagrams for numerical abundances of 6 species in Heliconia imbricata bracts for the 4 resource manipulation treatments. Numbers are values for partial correlations. Thick bars connecting circles are partial correlations significant at the $P<0.05$ level. Thin bars are partial correlations significant at the $P<0.10$ level. Dashed bars are non-significant partial correlations $(P>0.10)$. Abreviations are: $S Y=$ syrphids, $S T=$ stratiomyids, $C H=$ chironomids, $H I=$ hispines, $A 1=$ anoetid mites, $A 2=$ algophagid mites, $C O=$ copepods. See Table 1 for taxonomic information. See text for a description of the resource manipulation treatments

of flowers produced by the bract. I calculated multiple regressions to determine how well one could predict a species' abundance given the number of fruits and/or buds. Only two species showed significant regressions with respect to numbers of fruits in a bract $(P<0.01)$; (1) syrphids were negatively associated with number of fruits $(b=-5.20, a=-7.49, N=17)$, and (2) copedods were positively associated $(b=1.91, a=0.09, N=29)$ with the number of fruits. The data were log transformed because the transformation improved linearity. Bracts containing 0 individuals were not used in the calculations because they provided ambiguous information. That is, an empty bract occurs for one of three reasons; (1) no syrphids colonized the bract, (2) syrphids died because resources wer too low, or (3) syrphids died for some unknown cause. No other species showed a significant (i.e. $P<0.05$ ) association with fruits and/or buds.

Few significant numerical associations (partial correlations) can be detected among species in the control bracts. Figure 6 portrays these results in the second partial correlation diagram, labelled "control". Note that only 3 associations are significant $(P<0.05)$ out of 15 possible (when significance is adjusted for the probability that some significance is simply due to chance when 15 correlations are estimated). These were between syrphids and anoetid mites $(\mathrm{r}=-0.61, P<0.01)$, between hispine beetles and copepods $(\mathrm{r}=-0.42, P<0.05)$, and between chironomids and copepods $(\mathrm{r}=0.60, P<0.01)$. A fourth weak interaction is detectable between copepods and anoetid mites $(0.39, P<0.10)$.
Table 3. Treatment, height, interaction between treatment and height, and error matrices of sums of squares and cross products for the MANOVA of final numbers of fruits or buds in Heliconia inbricata bracts used in resource manipulations. See text for description of 4 treatments. Height refers to bract position in inflorescence as measured from bottom (oldest bract). Elements of the principal diagonal correspond to multivariate sums of squares for separate ANOVA's of the numbers of fruits and buds. See text for a description of treatments. Format of table follows that of Morin 1983

\begin{tabular}{|c|c|c|c|}
\hline \multirow[t]{2}{*}{ Matrix (df) } & \multirow[t]{2}{*}{ Variable } & \multicolumn{2}{|c|}{$\begin{array}{l}\text { Sums of squares or } \\
\text { cross products }\end{array}$} \\
\hline & & Fruits & Buds \\
\hline Error & $\begin{array}{l}\text { Fruits } \\
\text { Buds }\end{array}$ & $\begin{array}{l}903.200 \\
\ldots\end{array}$ & $\begin{array}{l}274.200 \\
850.800\end{array}$ \\
\hline Treatment & $\begin{array}{l}\text { Fruits } \\
\text { Buds }\end{array}$ & $\begin{array}{l}19.633 \\
\ldots\end{array}$ & $\begin{array}{r}45.933 \\
137.367\end{array}$ \\
\hline Height & $\begin{array}{l}\text { Fruits } \\
\text { Buds }\end{array}$ & $\begin{array}{l}147.350 \\
\ldots\end{array}$ & $\begin{array}{r}-231.375 \\
422.117\end{array}$ \\
\hline Interaction & $\begin{array}{l}\text { Fruits } \\
\text { Buds }\end{array}$ & $\begin{array}{l}39.117 \\
\ldots\end{array}$ & $\begin{array}{r}13.258 \\
36.883\end{array}$ \\
\hline
\end{tabular}

Univariate and multivariate tests

Tests for treatment effects

\begin{tabular}{|c|c|c|c|}
\hline & $\mathrm{F}$ & $\mathrm{df}$ & $p$ \\
\hline Fruits & 0.78 & $(3,108)$ & NS \\
\hline Buds & 5.81 & $(3,108)$ & $<0.001$ \\
\hline $\begin{array}{l}\text { Multivariate } \\
\text { (Wilk's Lambda) }\end{array}$ & 2.87 & $(6,214)$ & $<0.01$ \\
\hline
\end{tabular}

Wilk's Lambda)

Tests for height effects

\begin{tabular}{|c|c|c|c|}
\hline & $\mathrm{F}$ & df & $p$ \\
\hline Fruits & 8.81 & $(2,108)$ & $<0.001$ \\
\hline Buds & 26.79 & $(2,108)$ & $<0.001$ \\
\hline Multivariate & 20.75 & $(4,214)$ & $<0.001$ \\
\hline \multicolumn{4}{|c|}{ Tests for interaction effects } \\
\hline & $\mathrm{F}$ & df & $p$ \\
\hline Fruits & 0.78 & $(6,108)$ & NS \\
\hline Buds & 0.78 & $(6,108)$ & NS \\
\hline Multivariate & 0.94 & $(12,214)$ & NS \\
\hline (Wilks' Lambda) & & & \\
\hline
\end{tabular}

\section{Manipulating the resource}

Resources. Corolla production was not significantly different among treatments as determined by number of fruits produced. A two-way multivariate analysis of variance (MANOVA) was calculated to examine fruit and bud differences among treatments and differences among different heights (bract-order within the active region of the inflorescence) with respect to treatments (interaction between treatment and height). These analyses showed significant differences among treatments 

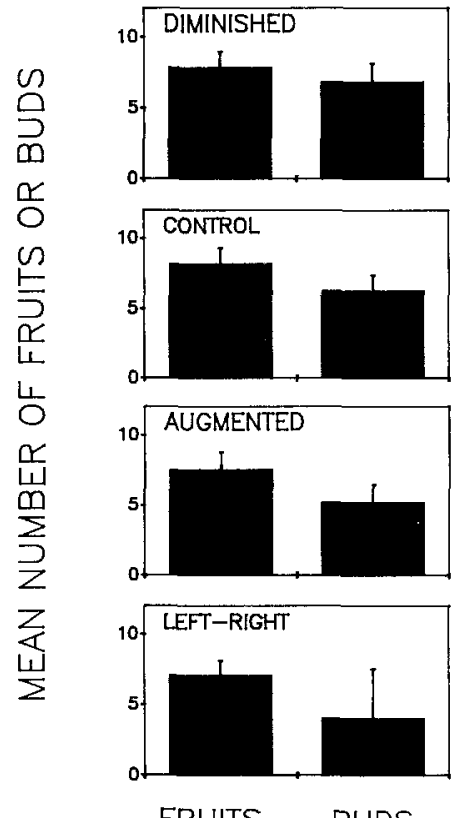

Fig. 7. Treatment means and $95 \%$ confidence intervals for Heliconia imbricata fruits and buds in resourcemanipulated treatment bracts. See text for description of treatments

when buds and fruits are considered simultaneously as dependent variables in the analysis (Table 3). Univariate analyses, however, indicate that bracts did not differ with respect to fruits $(P<0.51)$. The significant heterogeneity among treatments is due primarily to differences in numbers of buds, especially in the left-right treatments. Bracts in this treatment, by chance, had 2 to 3 buds fewer than bracts of other treatments (Fig. 7).

Homogeneity of fruits among treatments suggests that the actual number of flowers produced per bract were homogeneous among treatments. Heterogeneity of buds among treatments suggests that treatments differed with respect to corollas yet to be produced. Corollas not yet produced, however, do not affect the interpretation of these results.

Fruits and buds vary significantly with respect to height of bract (Table 3). This result is expected because bottom bracts are older and likely to have more fruits and fewer buds than higher bracts. No significant interaction between treatment and height, however, was found (Table 3). This result indicates that the significant variation in fruits due to height is not associated with variation in fruits due to treatment.

Arthropod assemblages. As mentioned above, 4 species were excluded from these analyses because of their low densities (less than 1 per bract). Logarithmic transformations were used for 5 species and copepods were squareroot transformed. Logarithmic transformations were used because they improved linearity (with respect to density-density associations) better than square-root transformations, the suggested transformation for data that represent counts (Sokal and Rohlf 1981). I used the square root transformation, for copepods, however, because it improved linearity more than the logarithmic transformation.

Treatments significantly affected (MANOVA, $P<$ 0.001 , Table 4) the abundance of species. The treatment effects important to this study are the differences between the control and the resource manipulated treatments. Most of these changes can be observed directly in Fig. 5.

Height did not significantly affect the abundance of species (multivariate Wilk's Lambda $=0.808$, d.f. $=12$, $206, P>0.05$ ) nor was there any significant interaction between height and treatment (multivariate Wilk's Lambda $=0.858$, d.f. $=36,455, P>0.05$ ). These results indicate that variation due to age of bract is not significant compared to variation due to the actual flower productivity of the bract.

It is not surprising that hispines did not respond, since corollas are not their food. It is also not surprising that syrphids cannot respond numerically. Syrphids cannot increase by recruitment because final instars leave the inflorescence and pupate on the ground and it is not likely that adults, which must first seek mates, will return to the same bract. Immigration and emigration are unlikely because larvae seldom move among bracts and cannot move between inflorescences. Further, since all bracts within a treatment inflorescence were treated identically, intra-inflorescence movement would not change the average conditions a syrphid was exposed to. That syrphids did not decrease in response to diminished resources suggests that they may be able to endure low resource conditions for up to 4 weeks.

To investigate how numerical associations among species change with respect to treatment I calculated partial correlations among the 6 species in each treatment. Figure 6 displays these results as partial correlation diagrams. Note that the diagram for each treatment is different. Also note that these diagrams should not be interpreted as interaction networks. Neither the magnitude nor the direction of any of the partial correlations necessarily represent interactions (Eberhardt 1970; Schluther 1984; Rosenzweig et al. 1985; Abramsky et al. 1986). Each correlation requires a separate investigation before the biological nature of the interaction it appears to reflect could be demonstrated. The diagrams simply demonstrate significant variation in the patterns of numerical associations among species when resources are manipulated.

In summary, manipulating resources resulted in differences in the abundance of chironomids, copepods, anoetid mites, and algophagid mites among bracts and resulted in differences in the numerical or statistical pairwise associations among species.

\section{Discussion}

Though the results of this study are complicated, they indicate clearly 3 things about the H. imbricata arthropod assemblage: (1) the assemblage subsists on a resource that is quite heterogeneous (Figs. 3, 4); (2) this heterogeneity directly modifies the outcomes of resource-mediated associations among species in complex ways that are not possible to predict without some knowledge of the resources (Figs. 5, 6); and (3) other non-resource mediated associations are affected indirect- 
Table 4. Treatment and error matrices of sums of squares and cross products for the MANOVA of final syrphid, chironomid, hispine, anoetid, algophagid, and copepod densities in Heliconia imbricata bracts for the resource manipulations and controls. Elements of the principal diagonal correspond to multivariate sums of squares for separate ANOVA's of the densities of the 6 species. See text for a description of the 4 treatments. Format of table follows that of Morin 1983

\begin{tabular}{|c|c|c|c|c|c|c|c|}
\hline \multirow[t]{2}{*}{ Matrix } & \multirow[t]{2}{*}{ Species } & \multicolumn{6}{|c|}{ Sums of Squares or Cross Products } \\
\hline & & Syrph. & Chiron. & Hisp. & Anoet. & Algo. & Cope. \\
\hline \multirow[t]{6}{*}{ Error } & Syrphid & 79.16 & -2.79 & 13.71 & -46.29 & -48.66 & -161.89 \\
\hline & Chironomids & $\ldots$ & 72.21 & -8.48 & 25.84 & 13.45 & 27.64 \\
\hline & Hispine & $\ldots$ & $\ldots$ & 59.18 & -36.01 & -39.96 & -166.73 \\
\hline & Anoetids & $\ldots$ & $\ldots$ & $\ldots$ & 199.77 & 108.50 & 365.81 \\
\hline & Algophagids & $\ldots$ & $\cdots$ & $\ldots$ & $\ldots$ & 272.99 & 277.89 \\
\hline & Copepods & $\ldots$ & $\ldots$ & $\ldots$ & $\ldots$ & $\ldots$ & 5387.93 \\
\hline \multirow[t]{6}{*}{ Treatment } & Syrphid & 1.03 & 0.42 & -0.40 & 6.34 & 4.80 & 18.10 \\
\hline & Chironomids & $\ldots$ & 8.53 & 2.12 & 3.80 & 0.47 & -10.69 \\
\hline & Hispine & $\ldots$ & $\ldots$ & 0.82 & -1.84 & -1.96 & -9.93 \\
\hline & Anoetids & $\ldots$ & $\ldots$ & $\ldots$ & 41.55 & 31.80 & 124.66 \\
\hline & Algophagids & $\ldots$ & $\ldots$ & $\ldots$ & $\ldots$ & 25.30 & 104.72 \\
\hline & Copepods & $\ldots$ & $\ldots$ & $\ldots$ & $\ldots$ & $\ldots$ & 467.17 \\
\hline
\end{tabular}

Univariate and multivariate tests

\begin{tabular}{llcl}
\hline Treatment tests & $\mathrm{F}$ & $\mathrm{df}$ & $p$ \\
\hline Syrphids & 0.470 & 3,108 & $\mathrm{NS}$ \\
Chironomids & 4.254 & 3,108 & $<0.01$ \\
Hispines & 0.500 & 3,108 & $\mathrm{NS}$ \\
Anoetid Mites & 7.470 & 3,108 & $<0.001$ \\
Algophagid Mites & 3.337 & 3,108 & $<0.02$ \\
Copepods & 3.121 & 3,108 & $<0.03$ \\
Multivariate (Wilk's Lambda) & 2.868 & 18,291 & $<0.001$ \\
\hline
\end{tabular}

ly (e.g. effects on the predatory chironomid or the facilitating hispines) by resource heterogeneity (Figs. 1 and 6).

Though both facilitation and competition are resource-mediated interactions, the importance of resources in assemblages of interacting species is often overlooked (Underwood 1986; Tilman 1987). Studies that have been well received, the "textbook" or "classic" examples, are usually those that have examined both resources and the distribution and abundance of species. Examples include space as a resource for barnacles (Connell 1961), particle size for Hydrobia snails (Fenchel 1975a, b, but see also Cherrill and James 1987), seeds for Darwin's finches (Grant 1986), bacteria for Paramecia (Gause 1934), silica for phytoplankton (Tilman 1977), flour for Tribolium beetles (Park 1948), and wheat for Tribolium (Crombie 1945). Note, however, that in majority of these studies populations were manipulated and resources were assumed to be initially homogeneous among experimental replicates, or were made so.

There is great utility in manipulating communities and monitoring changes in the community in response to the manipulation (Bender et al. 1984). For this reason many multi-species studies manipulate densities rather than resources (Tilman 1987). Macrocosm studies, for example, generally manipulate densities; usually communities are designed to have specific densities, established in large containers, and their dynamics are moni- tored (see, for examples, Wilbur 1982; Morin 1983; Murdoch et al. 1984; Folt 1986; Semlitsch 1987). If anything, the changes in community structure that occur in such studies are largely free of the effects of any substantial heterogeneity in resources. Similarly, the classic studies of Seifert and Seifert (1976) on Heliconia communities also manipulated densities and not resources.

In this study I have taken a different approach. I have manipulated resources and monitored changes in communities rather than manipulating communities and monitoring changes in communities. The resource manipulations in this study brought about a variety of changes in the abundance of species, both in relative abundance of species and in numerical associations. Further, the changes wer not simple changes. That is, augmented nutrients did not uniformly increase densities of all species nor did diminishing resources uniformly decrease densities of all species. That is, the affects are not additive.

These changes due to resource variation were dependent on the different ways the species use the resources, how they potentially interacted with one another (Fig. 1), and how the life-history and movement patterns of the species permitted differential exploitation of resource variation (Levins 1979; Naeem 1988). For example, microarthropods move freely among bracts within an inflorescence and go through several generations on an inflorescence and can respond numerically to within- 
bract resource variance. Mites ride phoretically on the hispine and hydrophilid beetles that move from inflorescence to inflorescence and therefore can respond to among inflorescence resource variation. Macroarthropods, however, are frequently confined to a bract (mosquitoes, chironomids) or face some risk in moving from bract to bract within an inflorescence (syrphids, stratiomyds, richardiids, hispine beetle larvae) and therefore complete only one generation on the inflorescence. Macroarthropods cannot move between inflorescences at all, except as adults.

Further, there are additional complexities not addressed in this study. For example, the system is highly structured (bracts are clustered in inflorescences, inflorescences are clustered in clones, and clones exhibit larger geographic scales of clustering). The effects observed in this study are likely to vary over different scales. Additionally, phytotelmata food-web architecture can vary considerably over different spatial and temporal scales (e.g., Kitching 1987). Although the food-web architecture was fairly constant in this study, from one replicate to the next, the architecture may vary outside the study area or seasonally. Note, however, that this food web is similar to that reported 14 years ago by Seifert and Seifert (1976b). Such issues of scale, however, only further emphasize the potential importance of resource heterogeneity and its effects on species abundance.

Two cautionary notes arise from this study. First, because microcosm systems are frequently set up with specific recipes for their nutrient base to ensure uniformity among macrocosms, their results may differ in complex ways if the experiments were repeated at different resource levels. Second, census data that pool results from communities over different areas or different years may combine data on communities that have entirely different structures at different resource levels. The problems of detecting interspecific competition in census data has attracted much attention (e.g., Eberhardt 1970; Schluter 1984; Rosenzweig et al. 1985; Abramsky et al. 1986). This issue is an important one because it is at the heart of much of the debate over the adequacy of the evidence for interspecific competition in structuring communities (Connor and Simberloff 1979; Schoener 1982; Connell 1983; Roughgarden 1983; Walter et al. 1986; Schoener 1986; see also, for review, May 1984; Diamond and Case 1986), much of which depends on analyzing census data, especially biogeographic census data (Colwell and Winkler 1984).

The abundance of species is undoubtedly affected by biotic interactions. But because many of these interactions are dependent, directly (competition or facilitation) or indirectly (predation or parasitism), on resource levels, predicting structure requires information on resources. Returning to the question this study set out to address, I conclude that rather simple manipulations of resources can cause complex, significant, and potentially predictable changes in these and perhaps other communities.

Acknowledgements. I thank T. Case, R.K. Colwell, M. Power, V. Resh, and W.P. Sousa and two anonymous reviewers for critical readings of the manuscript. I thank S. Allison, T. Grosholz, P.
Morin, S. Morse, D. Strong Jr., and S. Tjossem for discussion of the material presented in this paper. David and Deborah Clark provided much logistical support for this project. The Organization for Tropical Studies, the J.M. Noyes Foundation, Sigma Xi, and the Department of Zoology, University of California at Berkeley, provided funds for this research. Some funds were obtained from U.S. National Science Foundation grant (BSR86-04929) to R.K. Colwell. International Business Machines provided the computers, software, and peripherals used for this research. Finally, the friendship of Deborah and David Clark, P. Paaby, J.B. Peck, B. Mitchell, S. Morse, M. Quesada, G. Roderick, and S.F. Tjossem made this work possible.

\section{References}

Abramsky Z, Bowers MA, Rosenzweig ML (1986) Detecting interspecific competition in the field: testing the regression method. Oikos 47:199-204

Atkinson D, Shorrocks B (1981) Competition on a divided and ephemeral resource: a simulation model. J Anim Ecol 50:461471

Bender EA, Case TJ, Gilpin ME (1984) Perturbation experiments in community ecology: theory and practice. Ecology 65:1-13

Bookstein F, Chernoff B, Elder R, Humphries J, Smith G, Strauss R (1985) Morphometrics in evolutionary biology. Special publication 15, Academy of Natural Sciences, Philadelphia

Bronstein J (1986) The origin of bract liquid in a neotropical Heliconia species. Biotropica 18:111-114

Caswell H (1978) Predator-mediated coexistence: a nonequilibrium model. Am Nat 112:127-154

Cherrill AJ, James R (1987) Character displacement in Hydrobia. Oecologia $71: 618-623$

Chesson PL (1986) Environmental variation and the coexistence of species. In: Diamond J, Case TJ (eds) Community Ecology. Harper and Row, New York, pp 240-256

Colwell RK, Winkler DW (1984) A null model for null models in biogeography. In: Strong DR Jr, Simberloff D, Abele LG, Thistle AB (eds) Ecological communities: conceptual issues and the evidence. Princeton University Press, Princeton, pp 344-359

Connell JH (1961) The influence of interspecific competition and other factors on the distribution of the barnacle Chthalamus stellatus. Ecology 42:710-723

Connell JH (1983) On the prevalence and relative importance of interspecific competition: evidence from field experiments. Am Nat 122:661-696

Coughtrey PJ, Jones CRH, Martin MH, Shales SW (1979) Litter accumulations in woodlands contaminated by $\mathrm{Pb}, \mathrm{Zn}, \mathrm{Cd}$, and Cu. Oecologia 39:51-60

Crombie AC (1945) On competition between different species of graminivorous insects. Proc of the Royal Soc of London, B $132: 362-395$

Daniels GS, Stiles GF (1979) The Heliconia taxa of Costa Rica. Keys and Descriptions. Brenesia 15:1-150

Diamond J, Case TJ (1986) Overview: introductions, extinctions, exterminations, and invasions. In: Diamond J, Case TJ (eds) Community Ecology. Harper and Row, New York, pp 65-79

Digby PGN, Kempton RA (1987) Multivariate analysis of ecological communities. Chapman and Hall, London

Eberhardt LL (1970) Correlation, regression, and density dependence. Ecology 51:306-310

Edmondson WT (1970) Phosphorus, nitrogen, and algae in Lake Washington after diversion of sewage. Science 169:690-691

Edwards CA, Heath GW (1963) The role of soil organisms in the breakdown of leaf materials. In: Dockson J, Van der Drift J (eds) Soil organisms. North Holland, Amsterdam, pp 6-84

Fenchel T (1975a) Factors determining the distribution patterns of mud snails (Hydrobiidae). Oecologia 20:1-17

Fenchel T (1975b) Character displacement and coexistence in mud snails. Oecologia $20: 19-32$

Fish D, Beaver RA (1978) A bibliography of aquatic fauna inhabiting bromeliads (Bromeliaceae) and pitcher plants (Nepentha- 
ceae and Saraceniaceae). Proc of the 49th Florida Anti-mosquito Association pp 11-19

Folt C (1986) An experimental analysis of costs and benefits of zooplankton aggregation. In: Kerfoot CW, Sih A (eds) Predation: direct and indirect impacts on aquatic communities. University Press of New England, Hanover, pp 300-314

Frank JH, Lounibos LP (1983) Phytotelmata. Plexus Publishing, Medford

Gause GF (1934) The struggle for existence. Williams and Wilkens, Baltimore

Grant PR (1986) Ecology and evolution of Darwin's finches. Princeton University Press, Princeton

Hassall M, Turner JG, Rands MRW (1987) Effects of terrestrial isopods on the decomposition of woodland leaf litter. Oecologia (Berlin) 72:597-604

Holt RD (1977) Predation, apparent competition and the structure of prey communities. Theor Pop Biol 12:197-229

Holt RD (1984) Spatial heterogeneity, indirect interactions, and the coexistence of prey species. Am Nat 124:377-406

Huffaker CB (1958) Experimental studies on predation: dispersion factors and predator-prey oscillation. Hilgardia 27:343-383

Hutchinson GE (1961) The paradox of the plankton. Am Nat 95:137-146

Jeffries MJ, Lawton JH (1984) Enemy-free space and the structure of ecological communities. Biol J Linn Soc 23:269-286

Kikkawa J, Anderson DJ (1986) Community Ecology: Pattern and process. Blackwell Scientific Publications, Oxford, England

Kitching RL (1987) Spatial and temporal variation in food webs in water-filled treeholes. Oikos 48:280-288

Levins R (1968) Evolution in changing environments. Princeton University Press, Princeton

Levins R (1979) Coexistence in a variable environment. Am Nat 114:765-783

Luckinbill LS (1978) $\mathrm{r}$ - and K-selection in experimental populations of Eschericia coli. Science 202:1201-1203

Luckinbill LS (1979) Regulation, stability and diversity in a model experimental microcosm. Ecology 60:1098-1102

Maguire B Jr (1971) Phytotelmata: biota and community structure in plant held waters. Ann Rev Ecol Syst 2:439-464

Marshall DR, Jain SK (1969) Interference in pure and mixed populations of Avena fatua and A. barbata. J Ecol 57:251-270

May RM (1984) (Overview) In: Strong DR Jr, Simberloff D, Abele LG, Thistle AB (eds) Ecological communities: conceptual issues and the Evidence. Princeton University Press, Princeton, pp 1-16

Morin PJ (1983) Predation, competition, and the composition of larval anuran guilds. Ecol Monogr 53:119-138

Morin PJ, Wilbur HM, Harris RN (1983) Salamander predation and the structure of experimental communities and responses of Notophtalmus and microcrustacea. Ecology 64:1430-1436

Murdoch WW, McCauley E (1985) Three distinct types of dynamic behaviour shown by a single planktonic system. Nature $316: 628-630$

Murdoch WW, Scott MA, Ebsworth P (1984) Effects of the general predator, Notonecta (hemiptera), upon a freshwater community. J Anim Ecol 53:791-808

Naeem S (1988a) Resource heterogeneity fosters the coexistence of a mite and a midge in a pitcher plant. Ecol Monogr 58:215227

Naeem S (1988 b) Predator-prey interactions and community structure: chironomids, mosquitoes and copepods in Heliconia imbricata (Musaceae). Oecologia 77:202-209

Naeem S, Colwell RK (1990) Ecological consequences of heterogeneity of consumable resources. In: Kolasa J, Pickett STA (eds) Ecological heterogeneity. Springer, Berlin Heidelberg New York (in press)

Neill WE (1975) Experimental studies of microcrustacean competition, community composition, and efficiency of resource utilization. Ecology 56:508-526

Park T (1948) Experimental studies of interspecific competition. I. Competition between populations of the flour beetles Tribo- lium confusum Duval and T. castaneum Herbst. Ecol Monogr 18:267-307

Rashit E, Bazin M (1987) Environmental fluctuations, productivity, and species diversity: An experimental study. Microb Ecol $14: 101-112$

Roughgarden $J$ (1983) Competition and theory in community ecology. Am Nat 122:583-601

Rosenzweig ML, Abramsky Z, Kotler B, Mitchell W (1985) Can interaction coefficients be determined from census data? Oecologia 66:194-198

Satchell JE (1974) Litter-interface of animate/inanimate matter. In: Dickenson CH, Pugh GJF (eds) biology of plant litter decomposition, vol 1. Academic Press, London, pp 13-44

Schluter D (1984) A variance test for detecting species associations, with some example applications. Ecology 65:998-1005

Schoener TW (1982) The controversy over interspecific competition. Am Sci 70:586-595

Schoener TW (1986) Counters to claims of Walter et al. on the evolutionary significance of competition. Oikos 43:248-250

Seifert RP (1982) Neotropical Heliconia insect communities. The Quarterly Rev Biol 57:1-27

Seifert RP (1984) Does competition structure communities? Field studies of neotropical Heliconia insect communities. In: Strong DR Jr, Simberloff D, Abele LG, Thistle AB (eds) Ecological communities: conceptual issues and the Evidence. Princeton University Press, Princeton, pp 5463

Seifert RP, Seifert HF (1976a) A community matrix analysis of Heliconia insect communities. Am Nat 110:461-483

Seifert RP, Seifert HF (1976b) Natural history of insects living in inflorescences of two species of Heliconia. J New York Entomol Soc 84:233-242

Semlitsch RD (1987) Interactions between fish and salamander larvae: costs of predator avoidance or competition. Oecologia $72: 481-486$

Shorrocks B, Atkinson W, Charlesworth P (1979) Competition on a divided and ephemeral resource. J Anim Ecol 48:899908

Slatkin M (1974) Competition and regional coexistence. Ecology 61:163-177

Sokal RR, Rohlf FJ (1981) Biometry, 2nd Ed. W.H. Freeman and Co., San Francisco

Sousa WP (1979a) Experimental investigation of disturbance and ecological succession in a rocky intertidal algal community. Ecol Mongor 49:227-254

Sousa WP (1979b) Disturbance in marine intertidal boulder fields: the nonequilibrium maintenance of species diversity. Ecology $60: 1225-1239$

Sousa WP (1984) The role of disturbance in natural communities. Ann Rev Ecol Syst 15:353-391

Swift MJ, Heal OW, Anderson JM (1979) Decompostition in Terrestrial Ecosystems. Studies in Ecology, Vol 5, University of California Press, Berkeley

Tilman D (1977) Resource competition between planktonic algae: an experimental and theoretical approach. Ecology 58:338-348

Tilman D (1982) Resource Competition and Community Structure. Princeton University Press, Princeton, New Jersey

Tilman D (1987) The importance of the mechanisms of interspecific competition. Am Nat 129:769-774

Visser S (1986) The role of soil invertebrates in determining the competition of soil microbial communities. In: Fitter AH (ed) Ecological interactions in the soil environment: plants, micorbes and animals. Blackwell, Oxford

Walter GH, Hulley PE, Craig AJFC (1986) Speciation, adaptation, and interspecific competition. Oikos 43:246-248

Wilbur HM (1982) Competition between tadpoles of Hyla femoralis and Hyla gratiosa in laboratory experiments. Ecology $63: 278-282$

Witkamp M, Crossley DA Jr (1966) The role of arthropods and microflora in breakdown of white oak litter. Pedobiologia $6: 293-303$ 